\title{
Estudo de Vocábulos para Avaliação de Crianças com DeficiênCia Sem Linguagem OraL ${ }^{1}$ \\ StUdy OF Words FOR Assessing NON-SPEAKING CHILDREN WITH DisABILITIES
}

\author{
Andréa Carla PAURA ${ }^{2}$ \\ Débora DELIBERATO 3
}

\begin{abstract}
RESUMO: pesquisadores da área de comunicação suplementar e alternativa consideram a falta de instrumentos para avaliar crianças e jovens com necessidade complexa de comunicação. Este trabalho objetivou selecionar vocábulos para um instrumento de avaliação do repertório de vocabulário de crianças não-oralizadas com idade de dois a 11 anos e 11 meses. Para a seleção dos vocábulos foram realizados três estudos. O primeiro estudo identificou e descreveu instrumentos disponíveis para avaliação do vocabulário receptivo e suas listas de vocábulos. O segundo estudo identificou e descreveu pesquisas que apresentaram inventários ou listas de vocábulos empregados por crianças e seus parceiros de comunicaçáo. O terceiro estudo identificou o vocabulário relatado por pais e professores. Os vocábulos identificados nos três estudos foram analisados de acordo com: o número de ocorrência dos vocábulos; a classificação do sistema Picture Communication Symbols e uma classificação semântica e sintática. A partir dos estudos foram estabelecidos como critérios para a seleção dos vocábulos: os 45 vocábulos presentes nos três estudos; os vocábulos que tiveram ocorrência maior ou igual a cinco, considerando os três estudos, representando 167 (14,14\%) vocábulos; os vocábulos que estiveram presentes no estudo 1 ou 2, mas que foram citados pelas famílias, 183 (19,37\% de 945 vocábulos) ou pelas professoras 108 (11,43\% de 945 vocábulos). A lista de vocábulos apresentou 269 itens, classificadas em 18 temas semânticos e sintático e representa um instrumento inicial para profissionais da saúde e educação estabelecerem metas para a avaliação inicial de crianças e jovens usuários de sistemas de comunicaçáo suplementar e alternativa.
\end{abstract}

PALAVRAS-CHAVE: Educação Especial. Sistemas de Comunicação Alternativos e Suplementares. Paralisia Cerebral. Vocabulário. Linguagem Infantil.

ABSTRACT: Researchers in the field of Augmentative and Alternative Communication point out the lack of instruments for assessing children and young people with a complex communication needs. This study's focus is the selection of words for creating an instrument for the vocabulary range in non-speaking children aged two to eleven years and eleven months. Three studies were performed. The first study identified and described tools available for assessing receptive vocabulary and their respective word lists. The second identified and described research that presented word inventories or word lists. The third study identified the vocabulary reported by parents and teachers. The words that were identified in the three studies were analyzed according to: the number of times they occurred; the Picture Communication Symbols system classification; and a semantic and syntactic classification. Based on these studies the following criteria for vocabulary selection were established for word selection: the 45 words which appeared in all three studies, the words that occurred five times or more, considering the three studies, representing 167 (14.14\%) words; the words identified in study one or two, but that had been reported by the families - 183 (19.37\% out of 945 words) - or by teachers - 108 ( $11.43 \%$ out of 945 words). The word list was composed of 269 items, classified in 18 semantic and syntactic topics; it represents an initial tool for professionals in the field of health and education to set goals for beginning assessment of children and teenagers who are users of Augmentative and Alternative Communication systems.

KEYWORDS: Special Education. Augmentative and Alternative Communication. Cerebral Palsy. Vocabulary. Child Language.

\footnotetext{
${ }^{1}$ Trabalho realizado no Programa de Pós-Graduação em Educação da Faculdade de Filosofia e Ciências da Universidade Estadual Paulista - Unesp-Marília (SP), Brasil. Apoio: CNPq

${ }^{2}$ Doutora pelo Programa de Pós-Graduação em Educação da Faculdade de Filosofia e Ciências da Universidade Estadual Paulista "Júlio de Mesquita Filho"- Marília SP. Orientador de Disciplina do Curso de Pedagogia UNESP-UNIVESP.

${ }^{3}$ Professor Adjunto do Departamento de Educação Especial e do Programa de Pós-Graduação em Educação da Faculdade de Filosofia e Ciências da Universidade Estadual Paulista “Júlio de Mesquita Filho" - Marília SP. Livre- Docente em Comunicação Alternativa.delibera@marilia.unesp.br
} 


\section{INTRODUÇÁo}

A Comunicação Suplementar e Alternativa (CSA) pode ser considerada, atualmente, como um dos recursos que auxiliam o processo de aprendizagem e, consequentemente, o processo de inclusão de alunos com ou sem necessidades educacionais especiais (PAURA; DELIBERATO, 2007).

Beukelman e Mirenda (2007) relataram que o objetivo central da CSA é providenciar ao indivíduo oportunidade e capacidade para comunicar mensagens que possam interagir na conversação; participar em diferentes ambientes; aprender sua língua nativa; estabelecer e manter seu papel social, e satisfazer suas necessidades pessoais. A CSA pode ser usada como suporte para o desenvolvimento da linguagem e como recurso pedagógico, na área da educação e da educação especial.

A intervenção por meio da CSA deve ser iniciada precocemente, a fim de se evitar ou minimizar as diferenças entre a linguagem receptiva e a expressiva, bem como suas consequências no desenvolvimento global da pessoa com dificuldade de expressão, tanto no aprendizado, como em sua autonomia e integração social (MARTINSEN; VON TETZCHNER; 1996, DELIBERATO, 2013).

Crianças e jovens com severas dificuldades de comunicação podem ter dificuldade para elaborar e expressar suas mensagens e até mesmo para selecionar o vocabulário de que necessitam, para o seu recurso de comunicação. Os usuários de Comunicação Suplementar e Alternativa (CSA) que não são capazes de escolher seu vocabulário e suas mensagens dependem das decisôes realizadas por outras pessoas, como profissionais e familiares (BEUKELMAN; JONES; ROWAN, 1989; FRIED-OKEN; MORE, 1992; VON TETZCHNER, 2009). Identificar o vocabulário de um usuário de CSA pode ser uma tarefa difícil e demorada. Requer considerar as necessidades comunicativas, objetivos, experiências pessoais, diferentes ambientes a participação do usuário e de uma equipe significante, como os profissionais, a família, amigos e a escola (ROMSKI; SEVCIK, 2005; BEUKELMAN; MIRENDA, 2007; DELIBERATO, MANZINI, 2012)

Yorkston et al. (1988) descreveram a seleção de vocabulário como "o processo de escolha de uma pequena lista de vocábulos ou itens apropriados vindos de um conjunto de todas as possibilidades". São muitas as técnicas ou procedimentos descritos para a seleçấo do vocabulário de crianças e jovens não-oralizados: revisão do vocabulário por meio de listas, entrevistas com cuidadores, diários de comunicação, inventários formais sobre o ambiente, lista de vocábulos em uma folha de papel em branco, seleção de vocábulos advindos dos sistemas de comunicaçáo ou conjuntos de símbolos, comparaçôes de listas de vocábulos com ajuda de software (YORSTON et al., 1988; ARVIDSON; LLOID, 1997; MILLIKIN, 1997; BEUKELMAN; MIRENDA, 2007).

As listas de vocabulário podem ser úteis, quando há a necessidade de individualizar o vocabulário para determinado usuário. As listas podem ajudar a reduzir omissóes de vocabulário importantes. Listas de vocabulário padronizadas têm sido desenvolvidas para várias idades, baseadas em análise detalhada dos ambientes específicos (FRIED-OKEN; MORE, 1992; YORKSTON et al., 1989, THOMAS; PFISTER; PETERSON, 2004). 
A seleção do vocabulário não deve ser uma tarefa única, mas um processo contínuo, uma vez que a atualização do vocabulário envolve verificar o quão frequentemente e sob quais circunstâncias o vocabulário está sendo usado.

O objetivo de selecionar vocábulos para a elaboração de um instrumento para identificação do repertório do vocabulário é contribuir para a otimização do processo de seleção e manutenção do vocabulário, favorecendo a comunicação de necessidades e desejos, expressóes de ajuda, conversação com trocas de turnos, variedade de temas, respeitando relações temporais e espaciais - e, assim, o desenvolvimento da linguagem. Dessa forma, a utilização de um instrumento de avaliação para identificação do vocabulário adquirido pela criança não-oralizada, com deficiência neuromotora, poderá facilitar e propiciar a implantação dos recursos de CSA nos ambientes naturais como a família e o contexto escolar (SMITH, 2003; DELIBERATO, 2013).

Pensando na necessidade da identificação do repertório do vocabulário, das crianças não-oralizadas, com o intuito de proporcionar melhores e mais possibilidades comunicativas, educacionais e sociais, foi definida a problemática desta pesquisa.

É possível selecionar vocábulos que auxiliem a identificação do repertório de vocabulário de crianças náo-oralizadas, com idade de dois a onze anos e onze meses, considerando o período escolar referente à Educação Infantil, o início do Ensino Fundamental e a possibilidade de intervenção precoce, por meio dos sistemas de CSA?

\section{Oвjetivo}

Selecionar vocábulos para uma proposta de um instrumento de avaliação que auxilie a identificação do repertório de vocabulário de crianças não-oralizadas com idade de dois a 11 anos e 11 meses, usuárias ou em fase de implantação de sistemas de comunicação suplementar e alternativa.

\section{Método}

A realização deste trabalho foi estruturada em três Estudos. O primeiro Estudo identificou e descreveu instrumentos - testes, escalas e inventários - de avaliação do vocabulário e suas respectivas listas de vocábulos. O segundo Estudo investigou estudos que apresentaram inventários e listas de vocábulos frequentemente mais utilizados por crianças e jovens. $\mathrm{O}$ terceiro Estudo buscou a identificação do vocabulário relacionado às preferências e situaçóes da rotina, relatados por familiares e professores em entrevistas norteadas por meio dos protocolos de identificação das habilidades comunicativas propostos por Delagracia (2007) e Paula (2007). A seleção dos vocábulos ocorreu a partir do relacionamento das listas de vocábulos originadas dos três Estudos.

De acordo com as recomendaçôes da Resolução 196/96 do Conselho Nacional de Saúde, este projeto de pesquisa foi submetido à apreciação do Comitê de Ética da Faculdade de Filosofia e Ciências da UNESP de Marília (Parecer no 1311/2007).

O primeiro estudo identificou e descreveu instrumentos de avaliação do vocabulário receptivo e suas listas de vocábulos. Foram selecionados os instrumentos: ABFW Teste de 
Vocabulário de Befi-Lopes (2004); MacArthur Communicative Development Inventory: protocolo de palavras e gestos de Fenson et al (1993), PPVT - Peabody Picture Vocabulary Test of Dunn and Dunn (1981) e LAVE- List Assessment of Expressive Vocabulary adaptado por Capovilla e Capovilla (1997).

Para orientar a coleta de informaçóes a respeito dos instrumentos foi desenvolvido um roteiro (PAURA, 2009). Foram obtidos 973 vocábulos por meio da associação das listas dos vocábulos, 320 (32,90\%) vocábulos repetidos e lexias foram excluídos. A lista resultou em $653(67,10 \%)$ vocábulos.

O segundo estudo identificou e descreveu pesquisas relativas a inventários ou listas de vocábulos usados por crianças e seus parceiros de comunicação. Foram selecionados os estudos de Richards (1974) com 300 vocábulos; Beukelman, Jones e Rowan (1989) com 250 vocábulos, Fried-Oken e More (1992) com 212 vocábulos, Marvin, Beukelman, e Bilyeu (1994) com 332 vocábulos; Fallon, Light e Paige (2001) com 279 vocábulos, e por fim Bastos, Ramos e Marques (2004) com 245 vocábulos.

A soma dos vocábulos provenientes destes estudos totalizou 1.618 (100\%) itens. Após a exclusão dos vocábulos repetidos e das lexias 1.077 (66,55\%), foram considerados 541 $(33,45 \%)$ vocábulos.

O terceiro estudo identificou o vocabulário a respeito da rotina relatado em entrevistas por 12 mães de 12 crianças e jovens e quatro professoras, acerca de nove alunos não-oralizados usuários de comunicação suplementar e alternativa assistidos por um centro de atendimento especializado de uma cidade do interior do Estado de São Paulo, utilizando o Protocolo de avaliação das habilidades comunicativas para alunos não falantes em situação familiar e escolar, proposto por Delagracia (2007) e Paula (2007). Para este estudo, dentre as habilidades focalizadas pelo protocolo de avaliação das habilidades comunicativas para alunos não falantes, em situação familiar, foram considerados somente os itens relacionados às preferências, rotinas, atividades diárias, ajuda em serviço doméstico e os parceiros de comunicação. Assim, foram selecionados trechos dos relatos obtidos nas entrevistas e distribuídos em eixos temáticos, a partir dos quais foram delineadas as unidades e temas de análise do material escrito: identificação das atividades de rotina semelhantes encontradas no relato das famílias e professoras; e identificação do vocabulário no relato dos familiares e professoras - substantivos, verbos, adjetivos e advérbios relatados das suas rotinas. A lista de vocábulos totalizou 560 vocábulos; 347 proveniente das entrevistas com as famílias e 213 proveniente dos relatos das professoras. Entretanto, observouse que dos 560 (100\%) vocábulos, 104 (18,60\%) foram comuns em ambos relatos: famílias e professoras.

A partir do resultado de vocábulos identificados nos três estudos foram estabelecidos critérios para a seleção dos vocábulos. Os vocábulos provenientes dos três estudos foram unidos, classificados e analisados. Para tanto, um banco de vocábulos foi criado, totalizando 1.401 vocábulos. Os vocábulos foram ordenados alfabeticamente e excluídos os vocábulos redundantes. Foram excluídos 220 vocábulos, perfazendo o total de 1.181, conforme Figura 1, a seguir: 


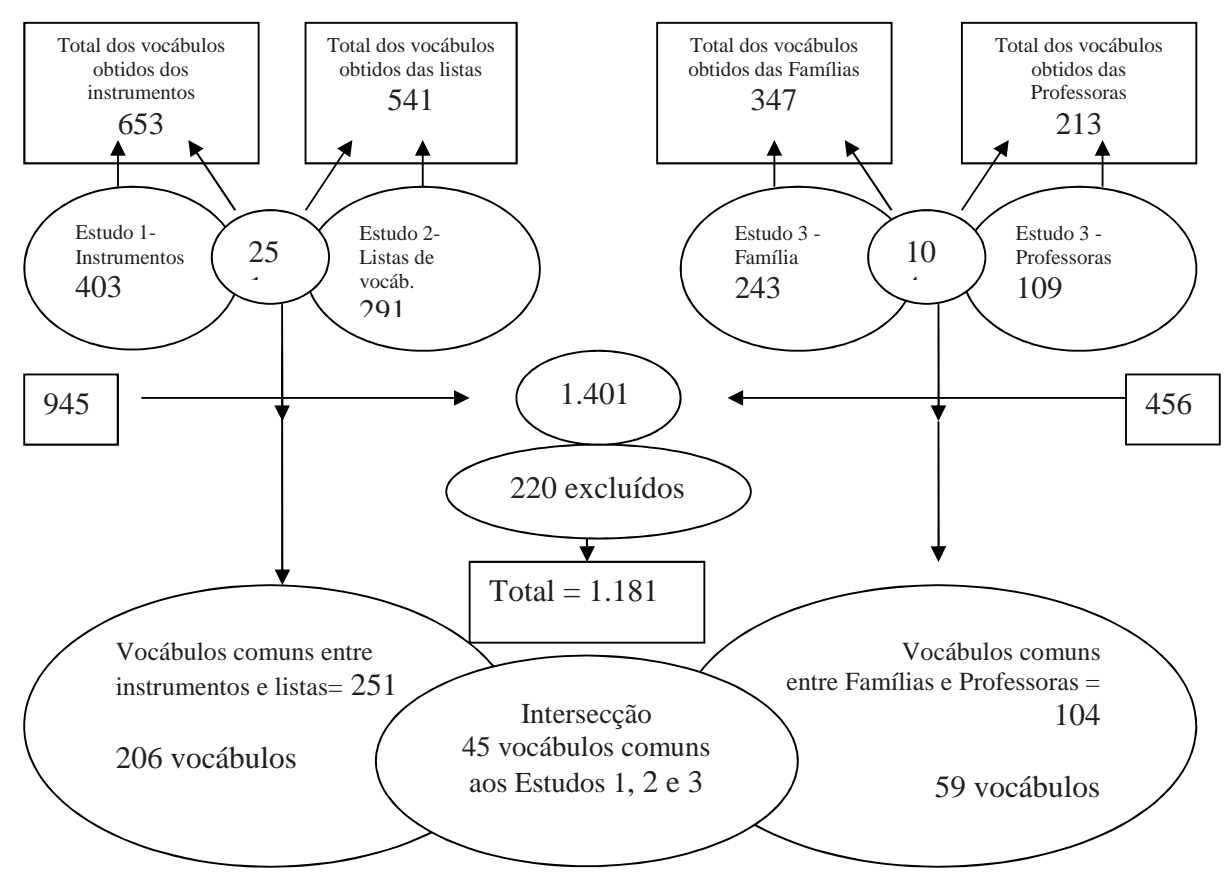

Figura 1 - Distribuição dos vocábulos considerando os Estudos 1, 2 e 3

A Tabela 1, a seguir, apresenta o relacionamento das listas de vocábulos do Estudo 1 - Instrumentos e Estudo 2 - listas, com os vocábulos obtidos dos relatos das famílias e professores. Essa Tabela pretende demonstrar qual a porcentagem de vocábulos presentes no Estudo 1 e 2, que foram mencionados pelos pais ou professores ou ainda por ambos.

Tabela 1 - Frequência de ocorrência de vocábulos relatada por familiares e professores, presentes nas listas de vocábulos provenientes de instrumentos e listas

\begin{tabular}{lccccccc}
\hline \multirow{2}{*}{ Vocábulos } & \multirow{2}{*}{ Total } & \multicolumn{2}{c}{ Família } & \multicolumn{2}{c}{ Professoras } & \multicolumn{2}{c}{$\begin{array}{c}\text { Famílias e } \\
\text { Professoras }\end{array}$} \\
\hline & $\mathrm{N}$ & $\mathrm{N}=347$ & $\%$ & $\mathrm{~N}=213$ & $\%$ & $\mathrm{~N}=104$ & $\%$ \\
\cline { 2 - 8 } Instrumentos & 653 & 153 & 44,10 & 83 & 38,95 & 61 & 58,65 \\
Listas & 541 & 132 & 38,05 & 81 & 38,00 & 56 & 53,85 \\
Instrumentos e listas & 945 & 183 & 52,73 & 108 & 50,70 & 72 & 69,23 \\
Vocáb. comuns entre & 251 & 102 & 29,40 & 56 & 26,30 & 45 & 43,26 \\
instrumentos e listas & & & & & & &
\end{tabular}

Com respeito aos 653 (100\%) vocábulos identificados nas listas de vocábulos dos instrumentos - Estudo 1, verificou-se que 153 (44,10\%) foram relatados pelas famílias, 83 $(38,95 \%)$ pelas professoras, ao passo que 61 (58,65\%) foram mencionados pelas famílias e professoras. 
Quanto aos 541 (100\%) vocábulos provenientes do Estudo 2 - listas, observou-se que 132 (38,05\%) foram relatados pelas famílias, 81(38 \%) pelas professoras e 56 (53,85\%) pelas famílias e professoras.

Ao se agruparem as listas dos Estudos 1 e 2, obteve-se o total de 945 (100\%) vocábulos, dos quais $183(52,73 \%)$ foram relatados pelas famílias, 108 (50,70\%) pelas professoras e 72 $(69,23 \%)$ pelas famílias e professoras.

Com relação aos 251 (100\%) vocábulos comuns entre as listas do Estudo 1 e 2 - Instrumentos e listas, 102 (29,40\%) foram relatados pelas famílias, 56 (26,30\%) pelas professoras e $45(43,26)$ pelas famílias e professoras.

Outras análises com base em três critérios ainda foram realizadas, após a união das listas de vocábulos: número de ocorrência dos vocábulos; classificação de acordo com o Sistema Picture Communication Symbols - PCS; e classificação semântica e sintática.

O primeiro critério de análise observou a frequência de ocorrência de cada vocábulo, considerando as 31 oportunidades de aparecimento para cada vocábulo, ou seja, a descrição de quatro instrumentos, no Estudo 1, a descrição de seis estudos com listas de vocábulos realizada, no Estudo 2, 12 entrevistas feitas com as famílias e nove entrevistas realizadas com as professoras, que, somados, totalizaram 31 oportunidades.

O segundo critério de análise baseou-se na classificação dos vocábulos segundo o sistema Picture Communication Symbols (PCS) (MAYER-JOHNSON, 2004). Esse sistema é provavelmente um dos mais utilizados atualmente por pessoas com deficiência que apresentam necessidades complexas de comunicação (NUNES, 2003). O PCS propóe a utilização de cinco cores, para classificar os itens da comunicação: laranja representa substantivos concretos e abstratos; amarelo é usado para pessoas e pronomes pessoais; verde para verbos; azul para adjetivos e advérbios; rosa para elementos sociais; e o branco para miscelânea, isto é, preposições, conjunçóes, adjuntos adverbiais, artigos, conceitos de tempo, alfabeto, cores, dias da semana.

O terceiro critério de análise realizou uma classificação semântica e sintática dos vocábulos em 24 temas: alimentos; animais; brinquedos, música, entretenimentos, esportes, instrumentos; rotinas e atividades da casa; comportamento e estado; rotinas e atividades da escola; lugares; móveis e aposentos; natureza; partes do corpo; pessoas; profissóes; transportes; utensílios e objetos; vestuário; expressóes sociais e interjeiçóes; perguntas e respostas; descritores; outros; verbos ou açóes; artigos; conjunções; preposiçóes e pronomes.

Optou-se por empregar o termo temas, ao invés de categorias, por abranger - além das categorias semânticas - as classes gramaticais. Os vocábulos identificados foram distribuídos em eixos temáticos, uma vez que os mesmos puderam ser representados em mais de um tema, com sobreposição de assuntos (MANZINI, 2004; OLIVEIRA, 2003).

A classificação proposta neste estudo contempla vocábulos de estrutura, ou funcionais, e vocábulos de conteúdo (BOWEN; MADSEN; HILFERTY, 1985): vocábulos de estrutura ou funcionais - artigos, conjunções, preposições e pronomes; e vocábulos de conteúdo-substantivos, verbos, adjetivos e advérbios. 
As classificações dos 1.181 itens da lista de vocábulos, de acordo com o PCS e sua natureza semântica e sintática, passaram por avaliações de dois juízes atuantes na área de Comunicação Suplementar e Alternativa, com a finalidade de verificar o índice de concordância.

\section{Resultados}

Com respeito à frequência de ocorrência dos vocábulos, dos 1.181 vocábulos identificados nos três estudos observou-se que 648 (54,87\%) vocábulos foram citados uma única vez, $1.014(85,86 \%)$ dos vocábulos ocorreram de uma a quatro vezes e somente 167 $(14,14 \%)$ vocábulos foram verificados com frequência de ocorrência igual ou maior que cinco.

A Tabela 2, a seguir, mostra o número de vocábulos por número de vezes de ocorrência, considerando os três Estudos, isto é, 31 possibilidades de aparecimento: os quatro instrumentos, seis estudos com listas de vocábulos, 12 entrevistas com as famílias e nove entrevistas com as professoras.

Tabela 2 - Número de vocábulos por frequência de ocorrência

\begin{tabular}{|c|c|c|}
\hline No de Ocorrências & No de Vocábulos & $\%$ \\
\hline 1 & 648 & 54,87 \\
\hline 2 & 182 & 15,41 \\
\hline 3 & 114 & 9,65 \\
\hline 4 & 70 & 5,93 \\
\hline 5 & 57 & 4,83 \\
\hline 6 & 27 & 2,29 \\
\hline 7 & 20 & 1,69 \\
\hline 8 & 21 & 1,78 \\
\hline 9 & 15 & 1,27 \\
\hline 10 & 3 & 0,25 \\
\hline 11 & 5 & 0,42 \\
\hline 12 & 4 & 0,34 \\
\hline 13 & 5 & 0,42 \\
\hline 14 & 4 & 0,34 \\
\hline 15 & 1 & 0,08 \\
\hline 16 & 1 & 0,08 \\
\hline 17 & 3 & 0,25 \\
\hline 18 & 1 & 0,08 \\
\hline TOTAL & 1.181 & 100,00 \\
\hline
\end{tabular}

Com respeito à classificação dos vocábulos pelo sistema Picture Communication Symbols, observou-se que a classificaçáo dos vocábulos substantivo concreto e abstrato representou a maior parte dos vocábulos da lista, (684; 57,92\%). Em segundo lugar de ocorrência, estiveram os verbos (177; 14,99\%), seguidos pelos adjetivos e advérbios (173; 
$14,65 \%)$, miscelânea $(63 ; 5,33 \%)$, pessoas e pronomes pessoais $(50 ; 4,23 \%)$ e elementos sociais (34; $2,88 \%)$.

\subsection{Critérios para definição dos VoCÁbUlos}

Após as análises provenientes do relacionamento entre os vocábulos dos Estudos 1, 2 e 3, foram definidos critérios baseados na frequência de ocorrência dos vocábulos, com ênfase nos de conteúdo; tais critérios levaram em conta os vocábulos de conteúdo habituais, ou seja, os mais comuns usados nos instrumentos de avaliação, citados nas listas de vocábulos dos estudos apresentados pela literatura e avalizados pelos relatos de familiares e professores.

Para a escolha dos vocábulos, foram selecionados: 1. os 45 vocábulos presentes nos três estudos: instrumentos, listas de vocábulos e entrevistas com pais e professores; 2 . os vocábulos que tiveram número de ocorrência maior ou igual a cinco, considerando os três Estudos. Assim, a soma do número de vocábulos que tiveram a frequência de ocorrência maior ou igual a cinco foi de 167 (14,15\%) vocábulos, dos 1.181 (100\%); portanto, foram desconsiderados os vocábulos com frequência de ocorrência de um a quatro, perfazendo 1.014 (85,85\%) vocábulos; 3. os vocábulos que estiveram presentes nos Estudos 1 ou 2, mas que foram citados pelas famílias 183 (19,37\% de 945 vocábulos); e 4. os vocábulos que estiveram presentes nos Estudos 1 ou 2, porém que foram citados pelas professoras 108 (11,43\% de 945 vocábulos), conforme pôde ser verificado na Tabela 6 .

Com a aplicação desses quatro critérios, foram selecionados 269 vocábulos. Esses 269 vocábulos sofreram classificação, de acordo com o sistema PCS e a classificação semântica e sintática.

Segundo a classificação do PCS, os 269 vocábulos apresentaram-se da seguinte forma:

Tabela 3 - Distribuição dos 269 vocábulos, de acordo com a classificação do PCS

\begin{tabular}{lcc}
\hline Classificação do PCS & $\mathrm{N}$ & $\%$ \\
\hline Pessoas e pronomes pessoais - Amarelo & 16 & 5,95 \\
Adjetivos e advérbios - Azul & 28 & 10,40 \\
Miscelânea - Branco & 4 & 1,50 \\
Substantivos concretos e abstratos - Laranja & 150 & 55,75 \\
Expressóes sociais - Rosa & 10 & 3,70 \\
Verbos - Verde & 61 & 22,70 \\
\hline Total & $\mathbf{2 6 9}$ & 100,00 \\
\hline
\end{tabular}

A Figura 2 a seguir apresenta a distribuição dos 269 vocábulos (segundas colunas do gráfico) de acordo com a classificação do sistema PCS, comparada à distribuição dos 1.181 vocábulos (nas primeiras colunas do gráfico). 


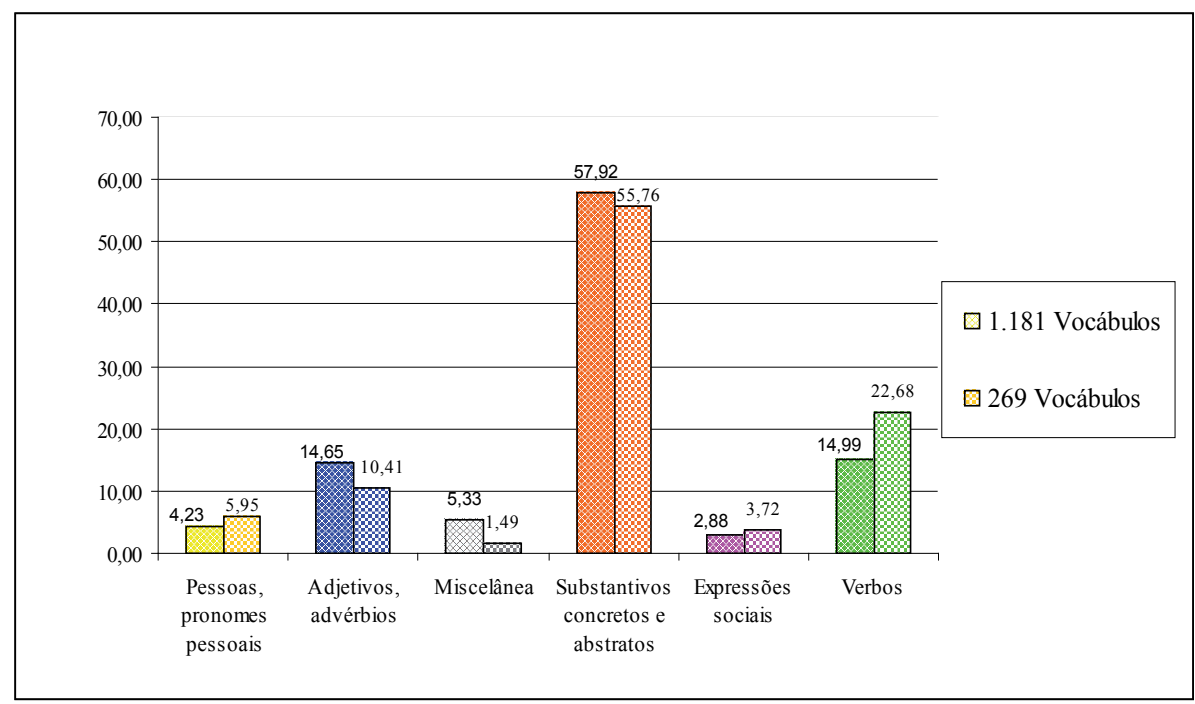

Figura 2 - Distribuição dos vocábulos selecionados versus vocábulos identificados nos Estudos 1,2 e 3

$\mathrm{Na}$ Figura 2, observou-se que dos 269 vocábulos selecionados os temas pessoas, pronomes pessoais; expressóes sociais e verbos apresentaram maior porcentagem de vocábulos do que a lista com 1.181 vocábulos; ao contrário dos temas adjetivos e advérbios; miscelânea e substantivos concretos e abstratos que apresentaram uma porcentagem menor que a lista de 1.181 vocábulos.

Quanto à classificação semântica e sintática, pôde-se perceber que a distribuição dos vocábulos mostrou-se, em ordem decrescente de porcentagem, da seguinte maneira:

Tabela 4 - Distribuição dos vocábulos do instrumento, de acordo com a classificação semântica e sintática

\begin{tabular}{lcc}
\hline Temas & No de Vocábulos & $\%$ \\
\hline Verbos ou ações & 60 & 22,30 \\
\hline Alimentos & 32 & 11,90 \\
\hline Descritores & 29 & 10,78 \\
\hline Rotinas e atividades da escola & 16 & 5,95 \\
\hline Pessoas, profissóes e pronomes pessoais & 16 & 6,32 \\
\hline Partes do corpo & 15 & 5,58 \\
\hline Lugares & 13 & 4,83 \\
\hline Móveis e aposentos & 12 & 4,46 \\
\hline Utensílios e objetos & 11 & 4,09 \\
\hline Animais & 11 & 4,09 \\
\hline Brinquedos, entretenimentos, esportes, instrumentos e música & 10 & 3,72 \\
\hline
\end{tabular}




\begin{tabular}{lcc}
\hline Perguntas, respostas e expressóes sociais & 10 & 3,72 \\
\hline Vestuário & 8 & 2,97 \\
\hline Transporte & 8 & 2,97 \\
\hline Comportamento & 5 & 1,86 \\
\hline Rotinas e atividades da casa & 5 & 1,86 \\
\hline Natureza & 4 & 1,49 \\
\hline Pronomes e preposiçóes & 3 & 1,12 \\
\hline TOTAL & 269 & 100 \\
\hline
\end{tabular}

Alguns agrupamentos foram realizados com respeito aos temas. Nesse sentido, ao tema pessoas foram somados os temas pronomes pessoais e profissóes; ao tema perguntas e respostas, acrescentou-se o tema expressóes sociais, e foram mantidos em apenas um tema, pronomes e preposiçôes. Esses agrupamentos ocorreram em virtude do pequeno número de vocábulos que ficariam em um número grande de temas. Dessa forma, os vocábulos foram distribuídos em 18 temas.

Segundo Barret (1997), quando a criança apresenta entre 50 e 100 vocábulos, seu inventário de verbos começa a aumentar, estendendo-se até o momento em que ela possui cerca de 500 vocábulos, em seu vocabulário; a partir desse instante, ocorre a equiparaçáo entre a proporção de verbos e os demais vocábulos. Os verbos possuem grande variedade semântica, o que dificulta sua rápida generalização, já que seu referente não é tão claro quanto o do substantivo, de maneira que sua aquisiçáo costuma ocorrer de forma mais gradual.

Bastos, Ramos e Marques (2004), entre outros objetivos, ao analisarem se há ou não explosão do vocabulário infantil ao redor de dois anos com crianças oralizadas, verificaram um índice maior de expressão na categoria substantivo. Os autores sugeriram para esta ocorrência a importância e frequência com que determinadas pessoas e objetos fazem parte dos contextos culturais das crianças, no mundo e no Brasil.

Nesse sentido, Befi-Lopes, Cáceres e Araújo (2007) realizaram um estudo com préescolares, com o objetivo de analisar quantitativamente a relaçáo entre o uso de substantivos e verbos, em situação de fala espontânea, em pré-escolares em desenvolvimento normal de linguagem, bem como de examinar a classificaçấo dos verbos utilizados. A análise dos dados demonstrou que os pré-escolares estudados usam mais verbos que substantivos, desde o segundo ano de vida.

Com respeito ao relato dos pais, a literatura tem demonstrado o reconhecimento do relato dos pais como auxílio à avaliação do vocabulário. Pine, Lieven e Rowland (1996) investigaram qual seria o método ideal para se avaliar o vocabulário das crianças, se o método de observação ou o de preenchimento pelos pais. Observaram que os pais sempre acabam superestimando o vocabulário de suas crianças, ao mesmo tempo em que a observaçáo fornece apenas uma medida indireta sobre o vocabulário. Concluíram que a melhor forma de se avaliar o vocabulário é combinar as informaçóes sobre a entrevista materna e as medidas de observação. Os achados estão de acordo com a pesquisa de Deliberato e Manzini (2012). That et al. (1999) 
verificaram a eficácia do MacArthur Communicative Development Inventories, em dois estudos, e validaram o apoio dos pais para a detecção de crianças com alteração de linguagem.

Befi-Lopes e Galea (2000), ao verificar o desempenho lexical em crianças de 2,8 a 6,5 anos de idade, com alterações no desenvolvimento da linguagem, consideraram que seria de grande valia a realização de estudos para a criação de protocolos nos quais os pais pudessem auxiliar a avaliação lexical das crianças falantes do português do Brasil. Os métodos de preenchimento de protocolos, para os pais verificarem o desempenho lexical de seus filhos, devem fazer parte da complementação das avaliações formais e de observaçóes realizadas com a criança e o avaliador.

Lamônica, Chiari e Pereira (2000), estudando a recepção lexical de 80 indivíduos com paralisia cerebral espásticos e atetóides e de um grupo-controle composto por 62 indivíduos, com idade cronológica de sete a 16 anos, por meio de prova de reconhecimento semântico comparada com o desempenho receptivo compreendido pelos familiares por meio de um inventário de habilidades receptivas, perceberam que a opção por um inventário que solicitasse o auxílio familiar foi extremamente importante, principalmente por avaliar indivíduos severamente comprometidos, pois a situação de avaliação é momentânea e a compreensão dos resultados pode ficar vinculada ao comportamento momentâneo do indivíduo participante. Mcdougall, Vessoyan e Duncan (2012) investigaram a avaliação de usuários de sistemas gráficos na faixa etária de seis a 21 anos, por meio do uso de métodos tradicionais e computadorizados. Em ambos os métodos utilizados para a avaliação, os pesquisadores indicaram a necessidade de identificar o vocabulário necessário para os recursos de comunicação independente do seu comprometimento. Os autores demonstraram que o uso da tecnologia, como no caso do uso do Test of aided-communication symbols performance (TASP) (BRUNO, 2007) poderia oferecer informaçóes a respeito das questóes linguísticas dos usuários de sistemas gráficos.

\section{ConsideraçóEs FinAIS}

Com a aplicação dos critérios, a lista de vocábulos apresentou 269 itens, classificadas em 18 temas semânticos e sintáticos (APÊNDICE A). A lista de vocábulos selecionada representa um instrumento inicial para profissionais da saúde e educação estabelecerem metas para a avaliação inicial de crianças e jovens com necessidades complexas de comunicação, usuários de sistemas de comunicação suplementar e alternativa.

A utilização desta lista de vocábulos poderá ser realizada de diferentes modos: investigação com a criança sobre a compreensão dos vocábulos selecionados com a opção de escolha ou exclusão destes por ela, para seu recurso de comunicação ou, ainda, a seleção dos vocábulos pela família e professor. Assim, o profissional terá a possibilidade de comparar os achados, verificados com a criança, com as informaçóes coletadas pelos informantes.

Enfim, a lista de vocábulos selecionados pode ser considerada um ponto de partida para a avaliação dos profissionais da saúde e educação, principalmente fonoaudiólogos. Esses vocábulos podem servir como norteadores para as pranchas de comunicação possam ser mais funcionais. 


\section{APÊNDICE A - ClassificaÇáo dos Vocábulos}

Pessoas: amigo/ avó, vovó, avô, vovô/ bebê ou nenê/ criança/ eu/ irmã, irmão/ mãe, mamãe/ menina, menino/ mulher/ nós/ pai, papai/ pessoas/ professor, professora/ secretária/ tia, tio/ vizinho, vizinha

Alimentos: água/ arroz/ banana/ bolacha/ bolo/ café/ carne/ chocolate/ coca-cola/ comida/ danone/ doce/ feijāo/ gelatina/ laranja/ leite/ maçã/ macarrão/ mamão/ manteiga, margarina/ mingau/ ovo/ pão/ papinha/ pizza/ refrigerante/ remédio/ salada/ salgadinho/ sopa/ sorvete/ suco

Partes do corpo: barriga / boca/ braço/ cabeça/ cabelo/ corpo/ dedo/ dente/ joelho/ mão/ nariz/ olho/ pé/ perna/ rosto

Vestuário: bolsa/ calças/ casaco, jaqueta/ fralda/ roupa, tecido/ sapato/ tênis/ vestido

Brinquedos: bicicleta/ bola/ boneca/ brinquedo/ carrinho/ futebol/jogo/ jogo de encaixe/ música/ revista

Animais: cachorro/ cavalo/ coelho/galinha/ gato/ passarinho/ pato/ peixe/ porco/ urso/ vaca

Transporte: ambulância/ barco/ caminhão/ carro/ moto/ ônibus/ perua

Lugares: calçada/ campo/ casa/ chão/ escola/ estacionamento/ fazenda/ igreja/ loja/ piscina/ porta/ restaurante/ rua

Utensílios: caixa/ caneta/ colher/ copo / garfo/ luz/ mamadeira/ panela/ rádio/ telefone/ tv, televisão

Móveis e aposentos: banheiro /cadeira/ cama/ cozinha/ fogão/ geladeira/ mesa/ privada/ quarto/ quintal/ sala/ sofá

Natureza: árvore/ flor/ pedra/ praia

Rotina e atividades em casa: almoço/ aniversário/ banho/ jantar/ refeição

Rotina e atividades escolares: apagador/ atividade /biblioteca/ carteira escolar, mesinha/ colar/ computador/ desenho/ figura/ folha de papel/ giz de cera/ lápis/ livro/ lousa/ papel/ sala de aula/ tarefa

Comportamento: fome/ medo/ feliz/ quieto/ xixi

Expressôes sociais: sim /não/ oi/ tchau/ por favor/ por quê?// quando?/ quem?/ onde?/ obrigado

Verbos: abrir/ ajudar/ alimentar/ almoçar/ andar/ arrumar/ assistir/ bater/ beber/ brincar/ cair/ chutar/ coçar/ colocar/ comer/ comprar/ conseguir/ conversar/ correr/ dançar/ dar/ deitar-se/ descansar/ descer/ desenhar/ dormir/ empurrar/ enxugar/ escovar/ escrever/ esperar/ falar/ fazer/ fechar/ ficar/ gostar/ guardar/ ir/ jogar, brincar/ lavar/ ler/ machucar/ olhar/ parar/ passear/ pegar/ pintar/ pular/ querer/ rasgar/ sair/ sentar-se/ ter/ tirar/ tocar/ tomar/ trabalhar/ trocar/ usar

Adjetivos e advérbios: antes/ aqui/ atrás/ bom/ cedo/ dentro/ dia/ doente/ em cima/ embaixo/ fora/ frio/ grande/ hoje/ hora/ lá/ lado/ líquido/ mais/ manhã/ muito / nada/ noite/ pequeno/ quente/ sujo/ tarde/ tempo (horário)/ vermelho

Pronome: dela, dele, meu, minha 


\section{REFERÊNCIAS}

ARVIDSON, H. H.; LLOYD, L. L. Vocabulary selection. In: LLOYD, L. L.; FULLER, D. R.; ARVIDSON, H. H. Augmentative and alternative communication: a handbook of principles and practices. Massachussets: Allyn and Bacon, 1997.

BARRET, M. Desenvolvimento lexical inicial. In: FLETCHER, P.; MACWHINNEY, B. Compêndio da linguagem da criança. Porto Alegre: Artes Médicas, 1997.

BASTOS, J. C.; RAMOS, A. P. F.; MARQUES, J. Estudo do vocabulário infantil: limitaçôes das metodologias tradicionais de coleta. Revista da Sociedade Brasileira de Fonoaudiologia, São Paulo, v. 9, p. 1-9, 2004.

BEFI-LOPES, D. M. Vocabulário (Parte B). In: ANDRADE, C. R. F. et al. ABFW: teste de linguagem infantil nas áreas de fonologia, vocabulário, fluência e pragmática. Carapicuiba: Pró-Fono, 2004. p. 33-49.

BEFI-LOPES, D. M.; CÁCERES, A. M.; ARAÚJO, K. Aquisiçâa de verbos em pré-escolares falantes do português brasileiro. Revista CEFAC, São Paulo, v. 9, n. 4, p. 444-452, 2007.

BEFI-LOPES, D. M.; GALEA, D. E. S. Análise do desempenho lexical em crianças com alteração no desenvolvimento da linguagem. Pró-Fono: Revista de Atualização Científica, Carapicuiba, v. 12, n. 2, p. 31-37, 2000.

BEUKELMAN, D. R.; MIRENDA, P. Principals of assessment. In: Augmentative and alternative communication: management of severe communication disorders in children and adults. 2.ed. Baltimore: Paul H. Brookes, 2007.

BEUKELMAN, D.; JONES, R.; ROWAN, M. Frequency of word usage by nondisabled peers in integrated preschool classrooms. Augmentative and Alternative Communication, v. 5, p. 243-248, 1989.

BOWEN, J.; MADSEN, S.; HILFERTY, A. Vocabulary-oral language. In: TESOL: techniques and procedures. Rowley: Newbury House Publishers, 1985.

BRUNO, J. Test of aided-communication symbols performance. Solana Beach: Mayer-Johnson, 2006.

CAPOVILLA, F. C.; CAPOVILLA, A. G. C. Desenvolvimento linguístico na criança dos dois aos seis anos: traduçáo e estandardização do Peabody Picture Vocabulary Test de Dunn \& Dunn e da Language Development Survey de Rescorla. Ciência Cognitiva: Teoria, Pesquisa e Aplicação, São Paulo, v. 1, n. 1, p. 353-380, 1997.

DELAGRACIA, J. D. Desenvolvimento de um protocolo para avaliação de habilidades comunicativa para alunos não-falantes em situação familiar. 2007. 168 f. Dissertação (Mestrado em Educação) - Faculdade de Filosofia e Ciências de Marília, Universidade Estadual Paulista, Marília, 2007.

DELIBERATO, D. Comunicaçáo alternativa na escola: possibilidades para o ensino do aluno com deficiência. In: ZABOROSKI, A. P.; OLIVEIRA, J. P. Atuação da Fonoaudiologia na escola: reflexôes e práticas. 1 ed. Rio de Janeiro: WAK Editora, 2013, p. 71-90.

DELIBERATO, D., MANZINI, E. J. Identification of the Communicative Abilities of Brazilian Children with Cerebral Palsy in the Family Context. Communication Disorders Quarterly, v.33, p.195 201, 2012.

DUNN, L. M.; DUNN, L. M. Peabody Picture Vocabulary Test - Revised. Circle Pines, MN: American Guidance Service, 1981. 
FALLON, K. A.; LIGHT, J.; PAIGE, T. K. Enhancing vocabulary selection for preschoolers who require augmentative and alternative communication (AAC). American Journal of Speech-Language Pathology, v. 10, p. 81-94, 2001.

FENSON, L. et al. MacArthur communicative developmental Inventories: user's guide and technical manual. San Diego: Singular Publishing; 1993.

FRIED-OKEN, M.; MORE, L. An initial vocabulary for nonspeaking preschool children based on developmental and environmental language sources. Augmentative and Alternative Communication, v. 8, p. 41-56, 1992.

LAMÔNICA, D. A. C.; CHIARI, B. M.; PEREIRA, L. D. Avaliação da recepção lexical em paralíticos cerebrais. Revista Fonoaudiologia Atual, n. 14, p. 20-27, 2000.

MAYER-JOHNSON, R. The Picture Communication Symbols - P.C.S. Software Boardmaker. Porto Alegre: Clik Tecnologia Assistiva, 2004. 1 CD-ROM.

MCDOUGALL, S.; VESSOYAN, K.; DUNCAN, B. Traditional versus computerized presentation and response methods on a structured AAC assessment tool. Augmentative and Alternative Communication, v. 28, n. 2, p. 127-135, 2012.

MANZINI, E. J. Entrevista semi-estruturada: análise de objetivos e de roteiros. In: SEMINÁRIO INTERNACIONAL DE PESQUISA E ESTUDOS QUALITATIVOS, 2: a pesquisa qualitativa em debate. Bauru: SIPEQ, 2004. 1 CD- ROM

MARTINSEN, H.; VON TETZCHNER, S. Situating augmentative and alternative communication intervention. In: VON TETZCHNER, S.; JENSEN, M. H. Augmentative and alternative communication: european perspectives. San Diego: Singular Publishing Group, 1996.

MARVIN, C. A.; BEUKELMAN, D. R.; BILYEU, D. Vocabulary-use patterns in preschool children: effects of context and time sampling. Augmentative and Alternative Communication, v. 10, p. 224-236, 1994.

MILLIKIN, C. C. Symbol systems and vocabulary selection strategies. In: GLENNEN, S. L.; DECOSTE, D. C. Handbook of augmentative and alternative communication. San Diego: Singular Publishing Group, 1997.

NUNES, L. R. O. P. Linguagem e comunicação alternativa: uma introdução. In: NUNES, L. R. O. P. (Org.). Favorecendo o desenvolvimento da comunicaçâo em crianças e jovens com necessidades educacionais especiais. Rio de Janeiro: Dunya, 2003.

OLIVEIRA, A. A. S. A entrevista em educação especial: questóes metodológicas. In: MARQUEZINE, M. C.; ALMEIDA, M. A. A; OMOTE, S. (Org.). Colóquio sobre pesquisa em Educação Especial. Londrina: Editora UEL, 2003.

PAULA, R. Desenvolvimento de um protocolo para avaliação de habilidades comunicativas de alunos nãofalantes em ambiente escolar. 2007. 148f. Dissertação (Mestrado em Educação) - Faculdade de Filosofia e Ciências, Universidade Estadual Paulista, Marília, 2007.

PAURA, A. C. Estudo de vocábulos para proposta de instrumento de avaliação do vocabulário de crianças não-oralizadas. 2009. 135f. Tese (Doutorado em Educação) - Faculdade de Filosofia e Ciências, Universidade Estadual Paulista, Marília, 2009.

PAURA, A. C.; DELIBERATO, D. Comunicação Alternativa e/ou Suplementar como recurso de apoio no ensino do conteúdo pedagógico de criança deficiente incluída. In: CONGRESSO 
BRASILEIRO DE COMUNICAÇÃO ALTERNATIVA, 2., 2007, Campinas. Anais.... Campinas: UNICAMP, 2007. 1 CD - ROM.

PINE, J. M.; LIEVEN, E. V. M.; ROWLAND, C. Observational and checklist measures of vocabulary composition; what do they mean? Journal of Child Language, v. 23, n. 3, p. 573-89, 1996.

RICHARDS, J. C. Word lists: problems and prospects. RELC Journal, v. 5, n. 2, p.69-84, 1974.

ROMSKI, M. A.; SEVCIK, R. A. Augmentative Communication and Early Intervention: Myths and Realities. Infants \& Young Children, v. 18, n. 3, p. 174-185, 2005.

SMITH, M. M. Environmental influences on aided language development: the role of partner adaptation. In: VON TETZCHNER, S.; GROVE, N (Ed.). Augmentative and alternative communication: developmental issues. London: Whurr, 2003. p. 155-175.

VON TETZCHENER, S. Suporte ao desenvolvimento da comunicação suplementar e alternativa. In: DELIBERATO, D.; GONÇALVES, M. J.; MACEDO, E. C. (Org.). Comunicação alternativa: teoria, prática, tecnologias e pesquisa. São Paulo: Memnon Ediçóes Científicas, 2009. p. 14-27.

THOMAS, L.; PFISTER, H. P.; PETERSON, P. Issues Related to the Construction of a PurposeBuilt Domain-Specific Word Corpus. Australian Journal of Educational \& Developmental Psychology. v. 4, p. 13-28, 2004.

YORKSTON, K. M. et al. A Comparison of standard and user vocabulary lists. Augmentative and Alternative Communication, v. 4, p.189- 210, 1988.

YORKSTON, K. M. et al. Vocabulary selection: a case report. Augmentative and Alternative Communication,v. 5, n. 2, p. 101-108, 1989.

YORKSTON, K. M.; SMITH, K; BEUKELMAN, D. Extended communication samples of augmented communicators: a comparison of individualized versus standard vocabulaires. Journal of Speech and Hearing Disorders, v. 55, p. 217-224, 1990.

Recebido: 17/11/2011

Reformulado: 26/08/2013

Aprovado: 19/12/2013 
PAURA, A. C. \& DELIBERATO, D. 